\title{
LYGIA SIGAUD (1945-2009)
}

\section{José Sérgio Leite Lopes}

Lygia Sigaud legou-nos a plenitude daquilo que fez e dos planos do que estava por fazer. Sua carreira pode ser acompanhada através das diferentes variações em seu relacionamento com o campo empírico de pesquisa, onde a Zona da Mata pernambucana tem lugar especial. Durante toda a sua trajetória ela analisou de diversos ângulos as percepções e as apropriações da entrada efetiva do direito e suas condições de possibilidade no mundo tradicional da plantation canavieira. A solidez de sua etnografia de longa duração notabilizou-a no Brasil e no exterior. Sua morte interrompeu um trabalho de sistematização dessa contínua elaboração analítica no seu momento de maturidade, com mais de trinta anos de experiência empírica paralela à sua vivência acadêmica.

Na juventude, Lygia Sigaud passou pela experiência liminar do movimento estudantil secundarista, antes de entrar para a Escola de Sociologia e
Política da PUC do Rio de Janeiro, que foi, na década de 1960, importante celeiro de futuros cientistas sociais profissionais. Nos seus últimos anos de graduação em sociologia, trabalhava como jornalista na editoria internacional do Jornal do Brasil. Foi com essa experiência anterior que ingressou, em 1968, na primeira turma de mestrado do Programa de Pós-Graduação em Antropologia Social do Museu Nacional. Como também ocorreu com seus colegas de turma inicial, Lygia Sigaud participou do projeto Estudo Comparativo do Desenvolvimento Regional, fazendo um survey na Região Nordeste. Depois, no fim de 1969 e no primeiro semestre do ano seguinte, foi para a Zona da Mata pernambucana com Moacir Palmeira, já com sua pesquisa individual sobre as categorias usadas pelos trabalhadores rurais em relação à sua concepção de tempo e à hierarquia daquele mundo social específico. Ela escolheu como centro de suas preocupações a 
categoria nativa "direitos", como marcador do tempo histórico e como operador central na vida cotidiana da área estudada (Sigaud 2008a).

Em 1972, Lygia Sigaud foi a campo juntamente com os pesquisadores orientados por Palmeira e já começava a coletar material sobre o processo de expulsão, pelos patrões, dos trabalhadores residentes nos engenhos. Os patrões alegavam que com a efetivação dos direitos (preconizados no Estatuto do Trabalhador Rural, de 1963, e no Estatuto da Terra, de 1964), não podiam mais manter a maior parte dos moradores; já os trabalhadores e os sindicalistas alegavam que as expulsões eram motivadas pela sonegação dos direitos. Era também em relação aos direitos que eram identificados e se identificavam os dois segmentos da força de trabalho: os "fichados", com contrato e "com direitos"; e os clandestinos, sem contrato e "sem direitos" (Sigaud, 2008b). Os trabalhadores expulsos foram se instalando nas pequenas cidades da Zona da Mata, em novos bairros precários chamados de "ponta de rua". Dali passariam a ser recrutados por empreiteiros para os trabalhos nas propriedades canavieiras.

Essa pesquisa teve um segundo período de campo, em 1974, resultando na tese de doutorado defendida na USP, em 1977, e publicada dois anos mais tarde (Sigaud, 1979). Este livro se divide em duas partes. A primeira analisa a liquidação da morada, os mecanismos de expulsão dos trabalhadores, a ruptura e o enfrentamento entre estes e os patrões e, finalmente, o estabelecimento dos trabalhadores nas "pontas de rua" das pequenas cidades da área. A segunda parte percorre as novas formas de submissão da força de trabalho, faz uma etnografia da relação entre empreiteiros e trabalhadores "clandestinos" e descreve as estratégias contra o desemprego durante a entressafra. Os capítulos finais analisam a utopia dos trabalhadores do "engenho liberto", isto é, da improvável reunião entre as vantagens da ordem tradicional e os benefícios dos "direitos", e discutem a relação dos clandestinos com o sindicato. Sua análise sobre o aparente paradoxo da simultaneidade de uma idealização do passado da relação de morada, por parte dos trabalhadores residentes dos engenhos tradicionais, com a busca por direitos sociais, no presente, foi inspiradora do interesse crescente dos cientistas sociais e historiadores do país pelas concepções e pelos usos do direito por parte dos trabalhadores na história brasileira recente.

Por ter estudado as relações sociais na Zona da Mata pernambucana desde a virada da década de 1960 para 1970 até os anos recentes, Lygia Sigaud nos fornece um panorama completo das transformações ocorridas sucessivamente na área, que remetem a processos semelhantes ocorridos em outras partes do país. O desvendamento de formas de dominação tradicionais e de suas transformações em novas formas de dominação, através do acesso às experiências dos trabalhadores rurais na época de auge da ditadura militar, era motivo de seu entusiasmo diante da abertura de novas possibilidades de ação no mundo. Em 1973 fez, com Vera Echenique, uma etnografia do Segundo Congresso dos Trabalhadores Rurais, realizado pela CONTAG, em Brasília. Em maio de 1979 acompanhou o Terceiro Congresso da CONTAG, junto com outros colegas de pesquisa, e depois esteve presente durante as campanhas salariais e as greves na Zona da Mata pernambucana, iniciadas em setembro de 1979, e que voltaram a ocorrer, de forma generalizada, em 1980 e nos anos seguintes. Logo após o final da maior delas, a de 1980, Lygia Sigaud publicou a descrição e a análise do que observou e da documentação disponível (Sigaud, 1980). Em 1984, por solicitação de sindicalistas, coordenou um trabalho de levantamento do cumprimento das convenções coletivas firmadas após os movimentos grevistas. Coordenou também um censo dos processos trabalhistas, tendo como peçachave as "petições iniciais", que passavam pelas Juntas de Conciliação e Julgamento nas comarcas da área canavieira. Em seu esforço mais recente de reflexão sobre esse material, tratava de reconstituir os elos entre o ato de recorrer à Justiça e a história das relações sociais no mundo dos engenhos, no intuito de examinar o modo como as inovações jurídicas produzem efeitos sobre o mundo social (Sigaud, 2008b).

Na década de 1990 passou a analisar o fenômeno das ocupações de terra e a série de acampamentos de trabalhadores nos próprios engenhos, quando de um período de declínio das propriedades 
canavieiras, quando então reuniu uma equipe binacional de pesquisadores e alunos do PPGASMN e da École Normale Superieure de Paris para estudar diferentes aspectos dessas transformações. (Sigaud, 2000; Sigaud e L'Estoile, 2006). Em 2002, coordenou a exposição temporária "Lonas e Bandeiras", no Museu Nacional, resultado estético audiovisual da pesquisa sobre os acampamentos (Sigaud, 2003). A exposição pôs em cena as ocupações de terra na Zona da Mata pernambucana para um público mais amplo na cidade do Rio de Janeiro, em um de seus espaços simbólicos nobres, assim como trouxe para a universidade alguns dos seus protagonistas entre os trabalhadores para os debates que ocorreram na semana inaugural da exposição.

Dessa rica experiência Lygia Sigaud pôde se servir posteriormente para refinar a sua análise da entrada do direito (com todos os seus personagens) no mundo social, o que a ocupou até o final da vida. Nas décadas de 1990 e 2000, ela centrou sua atuação nas repercussões propriamente acadêmicas de sua produção intelectual, no Museu Nacional, em revistas internacionais, com equipes em centros de pesquisa franceses e, mais recentemente, com a antropologia e a sociologia da Unicamp e com equipes da Universidade de Buenos Aires. Seu investimento nos últimos anos foi no sentido de aprofundar o efeito explicativo de suas etnografias, dando-lhes uma perspectiva mais geral pelo uso sistemático de referências pertinentes à história social da antropologia, que ela bem conhecia e para a qual também deu contribuições. Inversamente, sua reflexão sobre a história social da antropologia podia trazer resultados originais por ser lastreada na sua longa experiência empírica particular, fornecendo motes e questões bem fundados que desvendam aspectos pouco explorados da prática teórica da disciplina.

Ao ser convidada para fazer a apresentação da tradução do clássico de Edmund Leach, Sistemas políticos da Alta Birmânia, Lygia Sigaud viu a ocasião de servir-se do instrumental de análise de trajetórias em um campo intelectual específico. Nessa alentada apresentação de 45 páginas (Sigaud, 1996), fez uma leitura meticulosa de várias fontes publicadas e de uma carta de circulação restrita ao King's
College, escrita logo após a morte de Leach por Stephen Hugh-Jones, enviada para ela pelo autor. Ao defrontar-se com a aceitação acadêmica de um antropólogo considerado herético e explicitamente desafiante dos principais autores da disciplina, Lygia Sigaud foi se interessando pelas condições de possibilidade da originalidade e da inovação científicas reconhecidas pela própria doxa estabelecida. Em seguida, praticou a crítica herética à leitura hegemônica do célebre "Ensaio sobre o dom", de Marcel Mauss (Sigaud, 1999), interessando-se pelas condições de possibilidade da formação da doxa da disciplina (Sigaud, 2007).

Sua pesquisa sobre direito e mundo social, por sua vez, estava prestes a culminar com um livro sistematizador das múltiplas elaborações já feitas em artigos anteriores. $\mathrm{O}$ tema das repercussões do direito nas transformações sociais, da história comparada das ocupações de terra e das reivindicações de reforma agrária em Pernambuco, Rio de Janeiro e Rio Grande do Sul, assim como o das condições sociais da originalidade na teoria antropológica, estão presentes nesses manuscritos em estado adiantado de redação (Sigaud, 2008b). Esse livro terá sua publicação aguardada por seus amigos e colegas com aquela ponta de mistério de uma obra inacabada.

Além do rigor acadêmico, da grande capacidade de pesquisa e do comprometimento institucional que a caracterizavam, Lygia Sigaud sempre manifestou um forte engajamento político na ampliação do processo de democratização no Brasil, através dos resultados de suas investigações científicas, através do assessoramento a trabalhadores rurais, através da participação em diretorias de associações universitárias. O sentimento de cidadania, de coisa pública e de solidariedade social foram uma constante em sua vida, precocemente abreviada. ${ }^{1}$

\section{Nota}

1 Este texto baseia-se na nota publicada na página da ABA e na página do PPGAS-Museu Nacional (feita em colaboração com Beatriz Heredia e Rosilene Alvim) e em artigo de minha autoria sobre a trajetória de Lygia Sigaud (Leite Lopes, 2009). 


\section{BIBLIOGRAFIA}

LEITE LOPES, José Sergio (2009), “A 'ponta do novelo': em busca da trajetória de Lygia Sigaud". Mana, 15, 1: 257-258.

SIGAUD, Lygia. (1979), Os clandestinos e os direitos. São Paulo, Duas Cidades.

. (1980), Greve nos engenhos. Rio de Janeiro, Paz e Terra. . (1996), "Apresentação". In: LEACH, Edmund. Sistemas politicos da Alta Birmânia. São Paulo, EDUSP. . (1999), "As vicissitudes do Ensaio sobre o Dom”. Mana, 5, 2: 89-124. . (2000). "A forma acampamento: notas a partir da versão pernambucana". Novos Estudos, 58: 73-92.

. (2007). "Doxa e crença entre os antropólogos". Novos Estudos, 77: 29-152. . (2008a). "A collective ethnographer: fieldwork experience in the Brazilian Northeast". Information sur les Sciences Sociales, 47: 71-97. . (2008b), "A ponta do novelo: um estudo sobre direito e regulação social”. Manuscrito.

SIGAUD, Lygia. (org.). (2003),. Lonas e bandeiras em terras pernambucanas. Rio de Janeiro, Museu Nacional/ Tecnopop.

SIGAUD, Lygia; D'ESTOILE, Benoît (org.). (2006), Ocupações de terra e transformações sociais: uma experiência de etnografia coletiva. Rio de Janeiro, Editora FGV. 